\title{
MORFOLOGIA DA CIDADE PERFURADA: PADRÕES ESPACIAIS DE RUÍNAS E TERRENOS VACANTES EM CIDADES PORTUGUESAS
}

\author{
EDUARdo BRITO-HENRIQUES ${ }^{1}$ \\ PAUlo MORGADO ${ }^{2}$ \\ DAVID CRUZ ${ }^{3}$
}

\begin{abstract}
RESUMO - Este artigo analisa as consequências do encolhimento urbano na forma da cidade, produzindo o que aqui designamos de 'cidade perfurada'. $\mathrm{O}$ estudo baseia-se num inventário das 'perfurações' no tecido urbano geradas pelo abandono - i.e., os espaços arruinados e vacantes - em quatro cidades portuguesas em declínio demográfico. Os resultados comprovam que ruínas e terrenos vacantes são presenças comuns nessas paisagens urbanas. No total, $7,7 \%$ da área urbana das quatro cidades corresponde a 'perfurações', mas em algumas cidades essa proporção chega aos $32 \%$. O estudo demonstra que as 'perfurações' geradas pelo abandono tendem a ocorrer dispersa e um pouco aleatoriamente nas cidades, tanto em posições centrais como periféricas. A extensão e dispersão das 'perfurações' parece variar consoante a cidade é mais ou menos densa e o encolhimento é mais ou menos antigo ou foi mais ou menos severo.
\end{abstract}

Palavras-chave: Abandono; arruinamento; terrenos vacantes; encolhimento urbano; morfologia urbana.

ABSTRACT - MORPHOLOGY OF THE PERFORATED CITY: SPATIAL PATTERNS OF RUINS AND VACANT LAND IN PORTUGUESE CITIES. This paper aims to analyse the consequences of urban shrinkage in city form, producing the so-called 'perforated city'. It is based on an inventory of 'perforations' in the urban fabric generated by abandonment - i.e., ruins and vacant land - in four shrinking Portuguese cities. The results show that ruins

1 Professor Associado e Investigador Efetivo do Centro de Estudos Geográficos do Instituto de Geografia e Ordenamento do Território da Universidade de Lisboa, R. Branca Edmée Marques, 1600 -276, Lisboa, Portugal. E-mail: eduardo@igot.ulisboa.pt

2 Professor Auxiliar e Investigador Efetivo do Centro de Estudos Geográficos do Instituto de Geografia e Ordenamento do Território da Universidade de Lisboa, R. Branca Edmée Marques, 1600 -276, Lisboa, Portugal. E-mail: paulo@campus.ul.pt

3 Bolseiro de Investigação do Centro de Estudos Geográficos do Instituto de Geografia e Ordenamento do Território da Universidade de Lisboa, R. Branca Edmée Marques, 1600 -276, Lisboa, Portugal. E-mail: fabio.d.cruz@igot.ulisboa.pt 
and vacant land are common in the four cities. In total, $7.8 \%$ of the urban area corresponds to 'perforations'. In some cities, the proportion reaches $32 \%$. The study also demonstrates that the 'perforations' tend to occur in a scattered and somewhat aleatory manner in the cities, in both central and peripheral positions. Albeit, the incidence and spatial position of ruins and vacancies appear to vary depending on if the city is more or less compact, and on the degree and temporality of shrinkage.

Keywords: Dereliction; ruination; vacant land; urban shrinkage; urban morphology.

RÉSUMÉ - MORPHOLOGIE DE LA VILLE PERFORÉE: RÉPARTITION SPATIALE DES RUINES ET DES TERRAINS VAGUES EN VILLES PORTUGAISES. Cet article analyse les conséquences du rétrécissement urbain sur la forme des villes. Létude est basée sur un inventaire des "perforations" du tissu urbain créés par l'abandon - c'est-à-dire des espaces ruinés et vacants - dans quatre villes portugaises en déclin démographique. On a constaté que les ruines et terrains vagues sont des présences communes dans ces paysages urbains : soit 7\% de leur aire urbaine en moyenne, mais jusqu'à 32\% dans certains cas. Ces "perforations" apparaissent en général de façon dispersée et quelque peu aléatoire, en position aussi bien centrale que périphérique. Leur taille et leur dispersion paraissent varier en fonction de la densité urbaine, de l’ancienneté du rétrécissement urbain et de sa sévérité.

Mots clés: Abandon; ruine; terrain vague; rétrécissement urbain; morphologie urbaine.

\section{INTRODUÇÃO}

A bibliografia internacional sobre encolhimento urbano (urban shrinkage) publicada nos últimos anos mostra a importância deste fenómeno na evolução atual das cidades. Cidades em encolhimento (shrinking cities) não são casos excecionais ou anómalos no mundo mas sim expressões de um fenómeno estrutural e em expansão no globo (Wiechmann, 2008), que pode ocorrer por razões diversas - desastres ambientais, motivos políticos, mudanças societais, crises económicas, etc. (Reckien \& Martinez-Fernandez, 2011).

O encolhimento urbano tem consequências de várias ordens nas cidades. Estão referenciados impactos económicos, financeiros e sociais como desemprego e pobreza (Bontje, 2004; Audirac, Cunningham-Sabot, Fol, \& Torres Moraes, 2012; Wiechmann \& Pallagst, 2012), agravamento dos défices orçamentais e endividamento (Panagopoulos \& Barreira, 2013; Haase, Rink, Großmann, Bernt, \& Mykhnenko, 2014), migrações seletivas (white-flight e brain drain) e envelhecimento da população (Rieniets, 2009). Impactes físicos relacionados com o abandono e deterioração do ambiente construído também foram identificados, como o aumento de habitações vagas (Wiechmann \& Pallagst, 2012; Couch \& Cocks, 2013), de sucatas industriais e baldios (Berger, 2006), demolições (Mallach, 2011), e o fecho de infraestruturas e equipamentos para racionalização de custos (Hollander, Pallagst, Schwarz, \& Popper, 2009; Haase et al., 2014).

Apesar de haver na bibliografia referências dispersas a este género de impactos físicos, investigações focadas nos efeitos do encolhimento urbano na estrutura espacial das cidades são escassas. Embora quer o crescimento quer o declínio tenham consequências 
na ocupação do espaço e na forma urbana, há uma diferença enorme no conhecimento acumulado sobre os efeitos de um e de outro. Como observava Hollander (2011, p. 21), é fácil medir os efeitos do crescimento em termos de novas construções e espaços urbanizados, mas medir os efeitos do abandono é difícil e, por isso, "as mudanças de ocupação do solo em áreas em declínio são um campo largamente por cartografar".

É nesta faceta menos 'cartografada' que o presente estudo incide. O objetivo é investigar como o encolhimento urbano se exprime na paisagem através da presença nas cidades de espaços arruinados e vacantes. Basicamente, propomo-nos estudar a geometria desses espaços - i.e., questões de número, configuração, tamanho e posição relativa -, o que significa abordar o encolhimento urbano e o abandono do edificado pela perspetiva da morfologia urbana. Embora em Portugal os estudos de morfologia urbana tenham estagnado entre os geógrafos como refere Fernandes $(2015)^{\mathrm{i}}$, talvez por a certa altura os terem achado descritivos, internacionalmente são um campo de investigação que se renovou nos últimos tempos e que está em voga (Reis \& Silva, 2015), muito graças ao desenvolvimento das Tecnologias de Informação Geográfica, sobretudo os Sistemas de Informação Geográfica (SIG) e a Deteção Remota (DR).

Neste estudo, baseando-nos num levantamento por DR das ruínas e terrenos vacantes em quatro cidades cuja população regrediu entre os censos de 2001 e 2011 - Barreiro, Guimarães, Lisboa e Vizela -, examinamos a ocorrência e localização deste tipo de elementos no espaço urbano. O que averiguamos são questões simples mas que perduram sem resposta: quão frequentes são as ruínas e os terrenos vacantes na paisagem das cidades portuguesas? que área ocupam? como se distribuem no espaço? surgem de forma fragmentada ou formam manchas contínuas? tendem a 'clusterizar-se' ou a dispersar-se aleatoriamente? como se localizam com relação ao centro e à periferia das cidades? - Respondendo a estas questões, o que poderá parecer um simples exercício de rastreamento das ruínas e terrenos vacantes servirá na verdade para questionar a forma como o encolhimento urbano se exprime espacialmente ou, dito noutros termos, para discutir a morfologia da 'cidade perfurada'.

O artigo organiza-se da seguinte forma. Começa com a definição do quadro conceptual de análise, posto o que vem a descrição da metodologia de pesquisa. A isso segue-se a parte de apresentação e discussão dos resultados, onde se procede à análise dos padrões espaciais das ruínas e dos terrenos vacantes nas quatro cidades em estudo. $\mathrm{O}$ artigo termina com a sistematização das principais conclusões.

\section{QUADRO CONCEPTUAL: A ‘CIDADE PERFURADA’ E AS SUAS 'PERFURAÇÕES’}

Uma cidade em encolhimento define-se como "uma área urbana densamente povoada que, por um lado, enfrenta perdas de população" e, ao mesmo tempo, "está a passar por transformações económicas com alguns sintomas de crise estrutural" (Wiechmann \& Pallagst, 2012, p. 261). O termo 'encolhimento' pode aplicar-se a toda uma área metropolitana, cidade, ou simplesmente parte de uma cidade (Martinez-Fernandez, Audirac, Fol, 
\& Cunningham-Sabot, 2012). Em rigor, é um conceito que se reporta a uma forma de evolução regressiva da população e/ou da economia, e não tanto a questões morfológicas.

Embora a expressão 'encolhimento' sugira a imagem de uma cidade cujo tamanho ou volume se contrai, não é imperioso que a contração demográfica se traduza num retraimento da área urbana. Como observaram Newman, Bowman, Lee, e Kim (2016), é possível que aumentos e diminuições da população produzam resultados diferentes na ocupação do espaço consoante a elasticidade que o sistema de planeamento confere aos limites da mancha urbana. Alguns estudos mostraram inclusive que a população pode diminuir e, paradoxalmente, o espaço construído distender-se, numa combinação de regressão demográfica e dispersão urbana (urban sprawl) (Schmidt, 2011).

Falar de 'encolhimento urbano' não será, portanto, a forma mais adequada de descrever, em termos estritamente morfológicos, o que sucede nas cidades em recessão demográfica e económica. O termo 'cidade perfurada' (perforiert Stadt), que Florentin (2010) propôs retomando uma expressão originária de Lütke Daldrup (2003), constitui, em nosso entender, uma alternativa melhor. Para Florentin (2010, p. 83), a 'cidade perfurada' descreve "uma nova era de cidades caracterizadas em simultâneo por um declínio demográfico e dispersão urbana", onde a paisagem passa "a estar 'perfurada' por 'buracos' físicos e pedaços de terrenos baldios" (Florentin, 2010, p. 87). Usar este conceito em sentido mais abrangente, como equivalente da cidade em encolhimento para efeitos de morfologia urbana, parece-nos, todavia, adequado e é com esse sentido que aqui sugerimos o seu emprego.

As 'perfurações' que temos em mente quando falamos da 'cidade perfurada' são os espaços devolutos e abandonados que pontuam o tecido urbano, i.e. espaços que - como Solà-Morales (1995, p. 120) resumiu - são "internos à cidade mas externos ao seu uso quotidiano" porque "existem fora dos circuitos efetivos da cidade e das suas estruturas produtivas". Esses espaços desbaratados e frequentemente esquecidos têm sido designados na literatura sob nomes diversos: dead spaces ("espaços mortos") (Coleman, 1982), TOADS (acrónimo de Temporary Obsolete, Abandoned, and Derelict Sites) (Greenberg, Popper, \& West, 1990), drosscape ("paisagem-escória") (Berger, 2006), zombie properties ("propriedades zombies") (Silverman, Yin, \& Patterson, 2012), terrains vagues ("terrenos vagos”) (Solà-Morales, 1995), brownfields (Alker, Joy, Roberts, \& Smith, 2000; Queirós \& Brito-Henriques, 2001), vacant land ("solo vacante") (Pagano \& Bowman, 2000), VLAS (acrónimo de Vacant Land and Abandoned Structures) (Newman et al., 2016), etc. Uma tão grande variedade terminológica dificulta a clareza e coerência conceptual. Assim, para traçarmos correspondências entre conceitos, podemos assumir que as nossas 'perfurações' urbanas correspondem basicamente ao que Pagano e Bowman (2000, p. 2) chamaram de vacant land, a saber: "terrenos de propriedade pública ou privada não utilizados ou abandonados, onde pode ter havido em tempos estruturas construídas, assim como terrenos que possuem estruturas abandonadas, degradadas, emparedadas, parcialmente destruídas ou arrasadas".

Tentando desenvolver o conceito, diremos que as 'perfurações' urbanas incluem espaços que se podem considerar abandonados em três sentidos distintos: (i) espaços 
abandonados em sentido estrito, i.e. que tiveram no passado ocupação regular por funções urbanas e a deixaram de ter; (ii) espaços que nunca tiveram esse género de ocupação e apenas se podem considerar abandonados porque foram preteridos ou deixados à margem pelo processo de desenvolvimento urbano; (iii) e, por fim, espaços que simplesmente estão expectantes, vivendo uma espécie de abandono presente determinado por um esperado uso futuro. Bowman e Pagano (2004), retomando um estudo clássico de Northam (1971), explicaram que aquele segundo tipo de espaços costumam ser lotes desprezados por terem formas ou tamanhos desadequados ou terem localizações sensíveis (declives acentuados, áreas inundáveis, proximidade de fontes poluentes, restrições de utilidade pública, etc.); já os terrenos expectantes correspondem a parcelas de reserva que autoridades públicas e empresas mantêm para acautelar necessidades futuras, bem como terrenos que são retidos por particulares por razões especulativas.

Daquela definição retira-se ainda que as 'perfurações' urbanas tanto podem incluir terrenos livres de construções como terrenos com edificações. Embora o conceito de vacant land de Pagano e Bowman (2000) se aplicasse aos dois casos, Newman et al. (2016) preferiram falar de VLAS em termos genéricos, reservando a expressão vacant land para os espaços sem construções, e o conceito de abandoned structures ("estruturas abandonadas") para os lotes com construções. Essa opção de reservar o termo 'terreno vacante' para as 'perfurações' urbanas sem edificações parece-nos adequada e será seguida neste estudo.

Obviamente, o facto de um espaço não ter edificações não é suficiente como critério para definir uma 'perfuração'. Espaços verdes urbanos e solo agrícola são tipicamente espaços sem construções mas que não estão vacantes, no sentido em que não estão desocupados nem sem uso. O abandono consiste numa desistência ou recuo do controlo humano sobre o uso do solo e na devolução do seu destino à agência dos elementos naturais (Munroe, van Berkel, Verburg, \& Olson, 2013; Németh \& Langhorst, 2014), o que não se observa nos espaços verdes urbanos planeados (parques e jardins).

No caso dos espaços edificados, não basta que estes se encontrem desocupados para poderem ser considerados 'perfurações'. Como Hillier, Culhane, Smith e Tomlin (2003) assinalaram, vacância e abandono não coincidem conceptualmente. Enquanto a vacância se refere ao simples facto de dada construção não ser utilizada, o abandono implica "negligenciar as responsabilidades de proprietário relativamente à manutenção física, financeira e funcional" da sua propriedade (Hillier et al., 2003, p. 93), cortando serviços como o abastecimento de água ou eletricidade (manutenção funcional), deixando de cumprir obrigações fiscais ou hipotecárias (manutenção financeira), e desinvestindo na conservação e reparação (manutenção física). Existirem construções vagas numa cidade é, em certos limites, aceitável e até 'natural', não apenas porque há inevitavelmente um diferimento entre os tempos da oferta e da procura do espaço construído, mas também devido à "vacância friccional", conceito que se refere à necessidade de haver sempre uma margem de habitações sem uso no mercado para se permitir a mobilidade das famílias (Couch \& Cocks, 2013). Os problemas surgem quando tais situações de vacância alcançam proporções elevadas e perduram no tempo. Então, duas hipóteses são possíveis: (i) não considerar todas as edificações vagas mas apenas as que persistem nesse estado para além 
de um determinado limiar temporal - o que levantará depois a dúvida de saber que limiar deve ser esse; (ii) ou, em alternativa, considerar apenas as construções vagas que patenteiam sinais físicos de negligência e degradação - as ruínas - para melhor ir ao encontro da noção de abandono. A nossa opção neste estudo recaiu em apenas considerar as construções em ruínas, assumindo portanto um critério mais restritivo de abandono baseado na sua evidência morfológica.

\section{METODOLOGIA DA INVESTIGAÇÃO: O MÉTODO DE RASTREAMENTO DAS 'PERFURAÇÕES’ URBANAS E A SELEÇÃO DAS MÉTRICAS}

\section{O processo de recolha de dados}

Os estudos que conhecemos de inventariação dos espaços abandonados das cidades foram desenvolvidos a partir de dados secundários ou com base em métodos indiretos e inferições. A maior parte usou informação sobre número e área de espaços abandonados apurada a partir de inquéritos aos serviços de habitação e urbanismo das cidades (Greenberg et al., 1990; Accordino \& Johnson, 2000; Pagano \& Bowman, 2000; Newman et al., 2016), sem controlo dos investigadores sobre critérios nem métodos de apuramento desses números. Outros estudos usaram dados inferidos a partir dos fogos vagos dos censos da habitação (Hollander, 2011, Brito-Henriques, 2017), de informação fornecida pelos correios sobre propriedades sem serviço postal ou com correspondência não recolhida (Hollander, 2011; Silverman et al., 2012), ou basearam-se na cartografia de ocupação de solo produzida oficialmente (Pearsall, Lucas, \& Lenhardt, 2014), cujo grau de resolução não desce ao nível do lote. Todos estes métodos têm limitações que os próprios estudos identificam. Hoje, porém, graças ao enorme manancial de imagens de satélite e de fotografias áreas verticais e horizontais disponibilizadas por diversas plataformas online, à política de dados abertos, e à interoperabilidade assegurada por algoritmos de migração de dados geográficos entre os vários programas de SIG disponíveis (sejam eles gratuitos, de código aberto e ou comerciais), os investigadores dispõem de uma oferta de recursos e meios já bastante rigorosos para que possam fazer recolha direta de dados por DR.

Estudos baseados neste género de métodos combinados, juntando foto-identificação a partir de ortofotomapas de alta resolução e de recursos do Google Earth, foram realizados recentemente com sucesso na identificação de solo vacante não edificado (Grădinaru et al., 2015). Neste estudo, seguimos uma metodologia semelhante que aplicámos também ao espaço edificado.

As fontes usadas foram, para as cidades de Barreiro e Lisboa, ortofotomapas digitais de alta resolução $(0,10 \mathrm{~m})$ de um voo de 2014 que cobriu os municípios litorais de Portugal Continental, acessíveis em Web Map Service (WMS) no website da Direção-Geral do Território. Para as cidades de Guimarães e Vizela, usaram-se ortofotomapas com resolução espacial de $0,30 \mathrm{~m}$, referentes a 2015, disponibilizados pelas autarquias. A outra fonte de informação principal foi o recurso Google Street View disponibilizado pela aplicação 
Google Earth, que proporciona registos fotográficos ao nível do solo com cobertura de $360^{\circ}$ e possibilidade de time-lapse. O time-lapse foi usado para garantir concordância temporal entre as imagens verticais e horizontais, ou para confirmar classificações por exercícios de interpretação espaço-temporal ${ }^{\text {ii }}$. Como fontes de informação complementares, usaram-se os censos da habitação (quadros sobre necessidades de reparação dos imóveis e tipo de ocupação) e cartografia integrada nos instrumentos de gestão do território (cartas de qualificação do solo).

O rastreamento das 'perfurações' urbanas foi feito por foto-interpretação das imagens acima identificadas. Foram consideradas três categorias de espaços que correspondem a concretizações do conceito de 'perfuração' (v. secção anterior neste artigo), cuja definição está sintetizada no quadro I, a saber: 'terrenos vacantes', 'ruínas' e 'logradouros de ruínas'.

Quadro I - Tipos de 'perfurações' urbanas e respetivos critérios de identificação.

Table I - Categories of urban 'perforations' and criteria for their identifications.

\begin{tabular}{|c|c|c|}
\hline Tipo & Definição & Critério de identificação \\
\hline$\underset{\widetilde{\Xi}}{\stackrel{\Xi}{\Xi}}$ & $\begin{array}{l}\text { estrutura imóvel produzida pela } \\
\text { tecnologia humana que foi } \\
\text { abandonada e, por não se encontrar } \\
\text { fisicamente íntegra, está incapacitada } \\
\text { de desempenhar a função para que } \\
\text { estava destinada }\end{array}$ & $\begin{array}{l}\text { qualquer estrutura imóvel, incluindo infraestrutura, que se } \\
\text { apresente destruída ou incompleta e com sinais de abandono } \\
\text { (sem iluminação, sem sinais de presença/utilização humana } \\
\text { regular, com lixo, detritos, vegetação espontânea, etc.), assim } \\
\text { como edifícios emparedados/entaipados }\end{array}$ \\
\hline 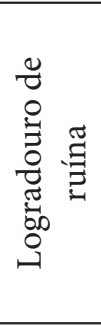 & $\begin{array}{l}\text { espaço não edificado anexo ou } \\
\text { envolvente de construção em ruína } \\
\text { que visualmente possa ser considerado } \\
\text { como parte integrante da mesma } \\
\text { propriedade }\end{array}$ & $\begin{array}{l}\text { posição em relação à ruína; existência de coberto vegetal } \\
\text { espontâneo ou seco, ou outro sinal de abandono e desleixo, } \\
\text { como a presença de detritos e resíduos, ferros-velhos, ou tanques } \\
\text { e piscinas sem água ou com água indevidamente tratada; estes } \\
\text { espaços só configuram polígonos autónomos quando } \\
\text { apresentam área superior à da construção em ruína a que estão } \\
\text { associados; caso contrário, são considerados parte da ruína }\end{array}$ \\
\hline 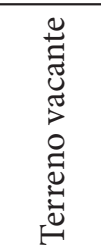 & $\begin{array}{l}\text { terreno sem ocupação e sem utilização } \\
\text { convencional (não edificado, não } \\
\text { agricultado e não ajardinado) } \\
\text { localizado no perímetro urbano }\end{array}$ & $\begin{array}{l}\text { terreno com solo nu ou com coberto vegetal espontâneo e a dar } \\
\text { sinais de abandono ou falta de cuidado, ou com vestígios de } \\
\text { demolição (entulho, impermeabilização do solo, etc.), situado no } \\
\text { interior de zonas construídas ou na sua contiguidade, e que por } \\
\text { isso forma um 'buraco' ou 'espaçamento' no tecido construído }\end{array}$ \\
\hline
\end{tabular}

O procedimento de inventariação decorreu da seguinte forma. Primeiro, para despistar possíveis áreas de maior concentração de ruínas, classificaram-se os quarteirões das cidades em função da presença de edifícios com grandes necessidades de reparação e da proporção de alojamentos vagos, usando os censos da habitação de 2011 desagregados ao nível da subsecção estatística. O passo seguinte consistiu na identificação dos terrenos vacantes, ruínas e respetivos logradouros através da foto-interpretação vertical dos ortofotomapas combinada com varrimento visual horizontal através do Google Street View. Pontualmente, foi necessário proceder a verificações no terreno. Por último, para validar a foto-identificação, foi feita uma despistagem de controlo confrontando os polígonos digitalizados com as cartas de qualificação de solo das quatro cidades em análise. 
O método de recolha de dados anteriormente descrito foi calibrado com verificações no terreno em duas áreas de teste da cidade de Lisboa (Ajuda e Bairro Alto), tendo-se comprovado que todos os elementos existentes no campo nessas duas áreas tinham sido identificados em gabinete com base no método descrito. Posteriormente, foi escolhida uma amostra aleatória de $20 \%$ das ruínas e dos terrenos vacantes identificados em Lisboa e Barreiro para verificação no terreno, tendo-se detetado erros inferiores a 5\% no primeiro caso e de $1 \%$ no segundo caso.

\section{A escolha das métricas espaciais e o tratamento dos dados}

Foram selecionados dois tipos de medidas de análise espacial para avaliar o comportamento espacial dos objetos em estudo e identificar padrões: i) medidas de distribuição espacial, designadamente medidas de centralidade (centroides) iii e elipses de distribuição (elipse do desvio padrão ou SDE, a partir de Standard Deviation Ellipse) ${ }^{\text {iv }}$; ii) e medidas de interpolação espacial (Densidade de Kernel) v.

Para o presente estudo foram calculadas três tipos de centroides, a saber: centroide das ruínas, que dá o ponto à menor distância física de todas as ruínas, feitos os somatórios das distâncias de todas com todas; o centroide dos logradouros de ruínas; e o centroide dos terrenos vacantes, que corresponde igualmente ao terreno vacante que se encontra a uma menor distância física de todos os outros terrenos vacantes, na mesma cidade. Combinando as SDE com a posição dos centroides, podemos verificar se há maior tendência de dispersão ou concentração dos objetos em estudo, assim como averiguar se essa maior concentração ocorre em locais perto do(s) centro(s) ou $\mathrm{da}(\mathrm{s})$ periferia(s) das cidades, respondendo deste modo a dois dos objetivos do estudo. A par das métricas de distribuição espacial dadas pelas medidas de centralidade e elipses de distribuição, a nossa metodologia ganha robustez científica porque amparada por métricas de interpolação, nomeadamente a Densidade de Kernel, que permite aferir os resultados obtidos pelas primeiras e detetar tendências de 'clusterização'.

\section{ANÁLISE E DISCUSSÃO DOS RESULTADOS}

Como referido anteriormente, a inventariação das ruínas e terrenos vacantes incidiu em quatro cidades que - pesem as diferenças - possuem em comum o facto de corresponderem a cidades em encolhimento porquanto todas perderam população no último período intercensitário: Barreiro, Guimarães, Lisboa e Vizela.

Neste grupo estão reunidos exemplos de cidades de dimensões contrastadas. Temos num extremo Lisboa, que segundo os censos de 2011 tinha uma população de 547733 habitantes numa área de cerca de $85 \mathrm{~km}^{2}$, e, no outro extremo, Vizela, com 10633 habitantes e uma área de $6,8 \mathrm{~km}^{2}$, de acordo com a mesma fonte e no mesmo ano (valores para a cidade estatística). Pelo meio aparecem Guimarães, que corresponde, para os padrões portu- 
gueses, a uma típica cidade média, com 47588 habitantes e área de $23,5 \mathrm{~km}^{2}$ (dados também para a cidade estatística do INE, segundo os censos de 2011), e a cidade do Barreiro, com 37729 habitantes concentrados numa área urbana de dimensão comparável à de Vizela (valores para o conjunto das antigas freguesias de Barreiro, Verderena e Alto do Seixalinho, que correspondem ao perímetro da cidade estatística do INE, segundo a mesma fonte).

As quatro cidades representam situações diferenciadas, tanto em termos de características morfológicas e funcionais, como no que respeita ao processo de encolhimento propriamente dito. Lisboa representa a situação de uma cidade-centro onde estão sedeados os principais polos de decisão política e económica do país e que, todavia, se encontra em regressão demográfica há mais de três décadas. $\mathrm{O}$ efeito da suburbanização associado à redução da dimensão das famílias e ao envelhecimento levaram a que a cidade perdesse $31,7 \%$ dos seus residentes entre 1981 e 2011, o que a coloca entre as cidades capitais europeias que mais encolheram nesse período. Ao mesmo tempo, Lisboa desindustrializou-se severamente: de 1981 para 2011, reduziu-se em quase três quartos o número de residentes com emprego no sector secundário, passando de cerca de 88600 ativos para 24200 (dados dos censos da população).

A cidade do Barreiro, integrada na Área Metropolitana de Lisboa, é o exemplo paradigmático de um antigo subúrbio industrial em crise. Trata-se de um centro urbano que conheceu um surto intenso a partir de finais do século XIX em consequência, num primeiro momento, do caminho de ferro - o Barreiro tornou-se em 1861 a testa de toda a rede ferroviária construída ao sul do Tejo - e, num segundo momento, da indústria, que teve um extraordinário progresso a partir da instalação do complexo industrial da Companhia União Fabril (CUF) ${ }^{\text {vi }}$ em 1908. No contexto português, a cidade do Barreiro é provavelmente o caso que mais se aproxima do modelo da company town, a típica cidade operária desenvolvida à sombra de uma grande empresa ou grupo económico, de cuja prosperidade fica dependente. O encolhimento drástico da cidade do Barreiro após 1980 foi, na verdade, um correlato direto do desmantelamento do grupo CUF/Quimigal e do colapso do modelo de industrialização que ele tipificava (Queirós, 2005): o sector secundário, que em 1960 empregava 60,7\% da população ativa do concelho, já não ocupava em 2011 senão uns escassos 19,1\% (dados dos censos da população).

Guimarães e Vizela representam situações diferentes, embora num quadro de tradição industrial também forte. A sub-região do Ave, onde as duas cidades se situam, é o território por excelência da industrialização difusa, das formas de ocupação dispersas do espaço, e da promiscuidade nos usos do solo. Uma maior indefinição nos limites da urbanização e um quadro caracterizado por múltiplas interpenetrações do rural, do florestal, do industrial e do urbano são as consequências disso.

Nem Guimarães nem Vizela devem o seu desenvolvimento tão univocamente à indústria como o Barreiro. Vizela foi um aprazível centro termal e Guimarães é uma cidade com oferta variada de comércio e serviços. As duas cidades diferem entre si porquanto uma é uma cidade histórica, com um centro de valor patrimonial reconhe- 
cido pela UNESCO, e a outra uma cidade jovem (só desde 1998), cujo desenvolvimento se fez por condensação de atividades e pessoas ao longo da estrada para Guimarães. Ao contrário de Lisboa e Barreiro, que estão em encolhimento há décadas, estas cidades entraram em regressão demográfica apenas no último período intercensitário, em resultado de um processo multicausal em que pesou a dispersão urbana, a crise económica (diminuição do emprego na indústria e construção civil), e mudanças societais (emigração de população jovem, redução da fecundidade, etc.): de acordo com os censos da população, a cidade de Guimarães perdeu 8,8\% dos habitantes entre $2001 \mathrm{e}$ 2011 (cerca de 4600 pessoas), e Vizela viu diminuir a sua população em 16,3\% (menos 2065 habitantes).

\section{Frequência e extensão das 'perfurações' urbanas}

Da inventariação que fizemos das 'perfurações' urbanas, ressalta como resultado que ruínas e terrenos vacantes são presenças bastante comuns na paisagem. Ao todo, no conjunto das quatro cidades, foram identificadas 2834 construções arruinadas, ocupando um total de 195 ha com os respetivos logradouros, a que somam mais 747 ha de terrenos vacantes.

O quadro II resume um conjunto de medidas úteis para avaliar a frequência e extensão das 'perfurações' urbanas. Pode reter-se como valor padrão uma razão média de 4,1 ruínas para 100 edifícios residenciais nas quatro cidades. Contudo, registam-se variações significativas entre elas. Embora todas tenham encolhido, a densidade e extensão do arruinamento é bastante variável, com o Barreiro a demarcar-se pela maior presença das ruínas: tomando como termo comparativo o número de ruínas por 100 edifícios, há nesta cidade cerca de duas vezes mais ruínas do que em Lisboa, e quatro vezes mais do que em Guimarães, o que parece relevar o papel da desindustrialização como fator de arruinamento urbano (Edensor, 2005; Mallach, 2011). Os dados sugerem também que cidades com historiais mais longos de encolhimento tendem a apresentar maior densidade de ruínas - vejam-se as situações de Lisboa e Barreiro face a Vizela e Guimarães no que respeita quer ao número de ruínas por 100 edifícios quer à proporção de área urbana por elas ocupada.

Os contrastes entre as cidades resultam mais vincados ainda se considerarmos não só as ruínas mas o somatório dos vários tipos de 'perfurações' e o espaço que ocupam. Enquanto em Lisboa e Guimarães o total das 'perfurações' recobre uma área equivalente a $6 \%$ da superfície urbana, em Vizela chega a 14\%, e no Barreiro ocupa quase um terço da área da cidade. Apesar da dificuldade de comparar estes números com os obtidos em outros estudos devido às diferenças de critérios e metodologia, a extensão das 'perfurações' no Barreiro parece ser de dimensão excecional mesmo para os padrões norte-americanos (Newman et al., 2016), cujas cidades por regra são menos densas e apresentam maiores proporções de vacâncias.

Apesar das ruínas serem mais numerosas, a maior parte do espaço urbano 'perfurado' são terrenos vacantes. No conjunto das quatro cidades, corresponde-lhes cerca de 
80\% da área total das 'perfurações' urbanas. Em Lisboa, com uma ocupação mais densa e um tecido urbano mais consolidado, a proporção de terrenos vacantes é mais baixa, mas fica ainda assim em quase 70\%. Já em Vizela e Barreiro, mais de $90 \%$ da área total de 'perfurações' corresponde a terrenos vacantes.

Quadro II - Número, extensão e densidade das 'perfurações' urbanas nas cidades em estudo.

Table II - Number, extension and density of urban 'perforations' in the four cities.

\begin{tabular}{|c|c|c|c|c|c|c|c|c|c|c|c|}
\hline & $\stackrel{\circ}{\rightrightarrows}$ & 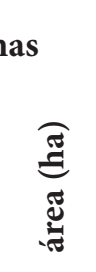 & $\begin{array}{l}\text { Logr } \\
\text { de }\end{array}$ & 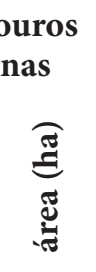 & $\begin{array}{l}\text { Ter } \\
\text { vac }\end{array}$ & 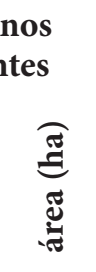 & 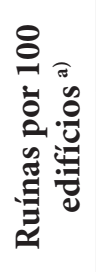 & 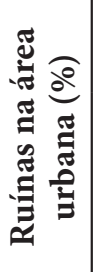 & 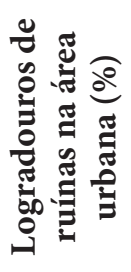 & 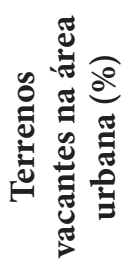 & 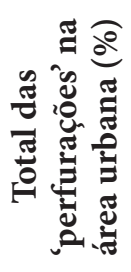 \\
\hline Barreiro & 382 & 16,1 & 36 & 3,6 & 169 & 194,8 & 8,9 & 2,4 & 0,5 & 29,2 & 32,2 \\
\hline Guimarães & 210 & 14,0 & 46 & 11,1 & 218 & 124,7 & 2,2 & 0,6 & 0,5 & 5,3 & 6,4 \\
\hline Lisboa & 2172 & 89,8 & 171 & 55,2 & 772 & 335,7 & 4,1 & 1,1 & 0,7 & 4,0 & 5,7 \\
\hline Vizela & 70 & 2,1 & 20 & 3,0 & 139 & 91,2 & 3,0 & 0,3 & 0,4 & 13,4 & 14,2 \\
\hline Total & 2834 & 121,9 & 273 & 72,9 & 1297 & 746,5 & 4,1 & 1,0 & 0,6 & 6,1 & 7,7 \\
\hline
\end{tabular}

a) Ponderado pelo número de edifícios residenciais fornecido pelos Censos 2011

Fonte: elaboração própria, a partir de dados primários e dados dos Censos 2011

Os terrenos vacantes podem incluir situações muito diferentes, e os exemplos de Vizela e Barreiro são ilustrativos disso. Em Vizela, por ser uma cidade mais jovem e imersa num contexto de forte dispersão urbana, os terrenos vacantes correspondem maioritariamente a antigo solo rústico recentemente reclassificado como urbano e que permanece expectante. Embora muitos sejam lotes individuais para construção de moradias ou prédios isolados, dispersos em áreas de urbanização recente, surgem também polígonos grandes, com alguns hectares, resultantes do loteamento de velhas quintas, bouças e matas. Muitos desses terrenos mantêm um coberto vegetal espontâneo, formando 'remendos' de incultos no meio do espaço construído e intromissões do natural no próprio espaço urbano, ao prolongarem a paisagem envolvente das bouças do Minho para dentro do perímetro urbanizado. A presença de postes de iluminação pública e de outros elementos infraestruturais nesses terrenos incultos, como caixas de eletricidade, ramais de ligação à água canalizada, e bocas de incêndio, confere a estes espaços uma aparência incerta, híbrida e transitória, que se diria característica de um processo de urbanização que ficou incompleto ou foi suspenso. No Barreiro, por sua vez, os terrenos vacantes correspondem sobretudo a espaços resultantes de demolições, a maior parte das quais ocorridas em solo que antes tinha uso industrial. Por isso a paisagem invoca aí mais a desolação dos territórios devastados. O solo aparece nu ou recoberto por uma vegetação secundária, baixa e esparsa. Há 'terras sujas', contaminadas por cinzas de pirites, lamas de zinco e fosfogesso. Fragmentos de solo impermeabilizado aparecem na paisagem como crostas, onde despontam rupícolas, por entre restos de ruínas isoladas, montículos de entulho, e por vezes sucatas. 
Ruínas, logradouros de ruínas e terrenos vacantes apresentam-se na paisagem em manchas de tamanhos diversos e com diferentes graus de fragmentação, que também variam de cidade para cidade. No quadro III sintetizam-se alguns parâmetros que ajudam a caracterizar as várias 'perfurações' desse ponto de vista.

Quadro III - Indicadores de fragmentação espacial das 'perfurações' urbanas nas cidades em estudo.

Table III - Measures of spatial fragmentation of the urban 'perforations' in the four cities.

\begin{tabular}{|c|c|c|c|c|c|c|c|c|c|c|c|c|}
\hline & & Ruínas & & & adour & & Terre & nos vac & ntes & Total & as perf & ações \\
\hline & 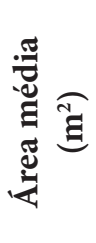 & 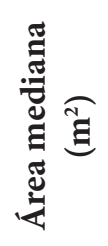 & 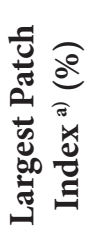 & 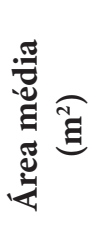 & 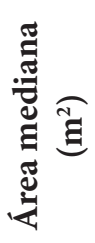 & 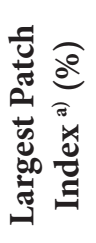 & 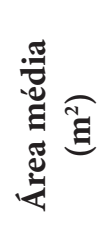 & 胥 & 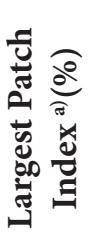 & 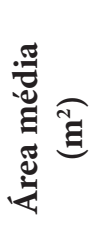 & 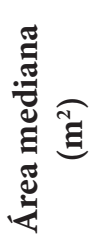 & 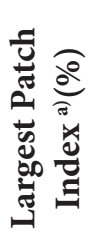 \\
\hline Barreiro & 420 & 127 & 5,8 & 993 & 232 & 45,0 & 11528 & 924 & 31,3 & 3653 & 186 & 28,6 \\
\hline Guimarães & 666 & 213 & 17,9 & 2422 & 1172 & 17,3 & 5719 & 2057 & 4,6 & 3161 & 682 & 3,8 \\
\hline Lisboa & 413 & 152 & 2,3 & 3314 & 667 & 11,2 & 4355 & 803 & 5,3 & 1548 & 204 & 3,7 \\
\hline Vizela & 306 & 134 & 23,2 & 1482 & 930 & 21,4 & 6561 & 2470 & 9,9 & 4206 & 1082 & 9,4 \\
\hline Total & 430 & 151 & - & 2724 & 678 & - & 5755 & 1150 & - & 2141 & 231 & - \\
\hline
\end{tabular}

a) Ver nota no texto

Fonte: elaboração própria, a partir de dados primários

A análise dessas medidas mostra que as ruínas são as 'perfurações' mais atomizadas, mais numerosas mas de menor área. A área média, a área mediana e o LPI (Large Patch Index) ${ }^{\text {vii }}$ destas são os mais baixos dos três tipos de 'perfurações'. Embora se encontrem em todas as cidades casos impressivos de grandes ruínas, normalmente associados a edifícios industriais, ou mais raramente a equipamentos, a maioria é composta por pequenas construções com áreas de implantação modestas (área mediana de $151 \mathrm{~m}^{2}$ no conjunto das quatro cidades), correspondendo a habitações, mas também a vários géneros de dependências (adegas, currais, tanques, etc.) e infraestruturas.

As ruínas com jardins, quintais ou outros logradouros de área superior à área edificada são pouco frequentes, não chegando a $10 \%$ no total das quatro cidades em estudo. Portanto, só uma pequena parte das construções arruinadas correspondem a formas de porosidade verde no tecido construído. Em todo o caso, não se pode desprezar o valor ambiental dos logradouros de ruínas, sobretudo em cidades maiores e mais densas. Em Lisboa e Guimarães, concretamente, totalizam umas dezenas de hectares e tendem a formar manchas com alguma expressão (em média, áreas de $3314 \mathrm{~m}^{2}$ em Lisboa e $2422 \mathrm{~m}^{2}$ em Guimarães).

Os terrenos vacantes são as 'perfurações' urbanas mais extensas e contínuas das cidades. Ao mesmo tempo, são também o tipo de 'perfuração' mais heterogéneo, onde se incluem polígonos de dimensões e formas mais díspares. Como se comprova pela análise dos mapas das 'perfurações' urbanas (figs. 1 a 4), em qualquer das quatro cidades se podem encontrar extensos 'remendos' de terrenos vacantes, alguns formando manchas 
contínuas de dezenas de hectares. Essas vacâncias de maior dimensão surgem sobretudo nas margens do espaço construído, ou formam espaçamentos intersticiais e descontinuidades na mancha urbana que contribuem para a fragmentação do tecido das cidades. Maioritariamente, correspondem a solo expectante ou, menos frequentemente, a espaços com algum tipo de condicionamento à construção ou ocupação urbana. Porque aparecem em áreas não normalizadas pelo desenho urbano, formam polígonos de contornos mais irregulares, trapezoidais. Grandes manchas de terrenos vacantes surgem ainda associados a brownfields e demolições industriais, como referimos anteriormente, e como corrobora Santos (2018). Isso sucede sobretudo no Barreiro, onde as maiores manchas ocorrem a nordeste, nos espaços da antiga CUF/Quimiparque, antes estudados por Queirós (2005), e parcialmente também em Lisboa (Zona Oriental). Contudo, tal não impede que, ao mesmo tempo, existam pequenos terrenos vacantes embutidos no tecido construído, associados a lotes devolutos, a produtos de demolições, ou ainda - raramente a servidões e restrições de utilidade pública. Situações dessas são pouco frequentes em Guimarães e Vizela, mas bastante comuns em Lisboa e no Barreiro, razão que explica as menores áreas medianas dos terrenos vacantes nessas duas cidades $\left(803 \mathrm{~m}^{2}\right.$ e $924 \mathrm{~m}^{2}$, respetivamente, contra $2057 \mathrm{~m}^{2}$ em Guimarães e $2470 \mathrm{~m}^{2}$ em Vizela).

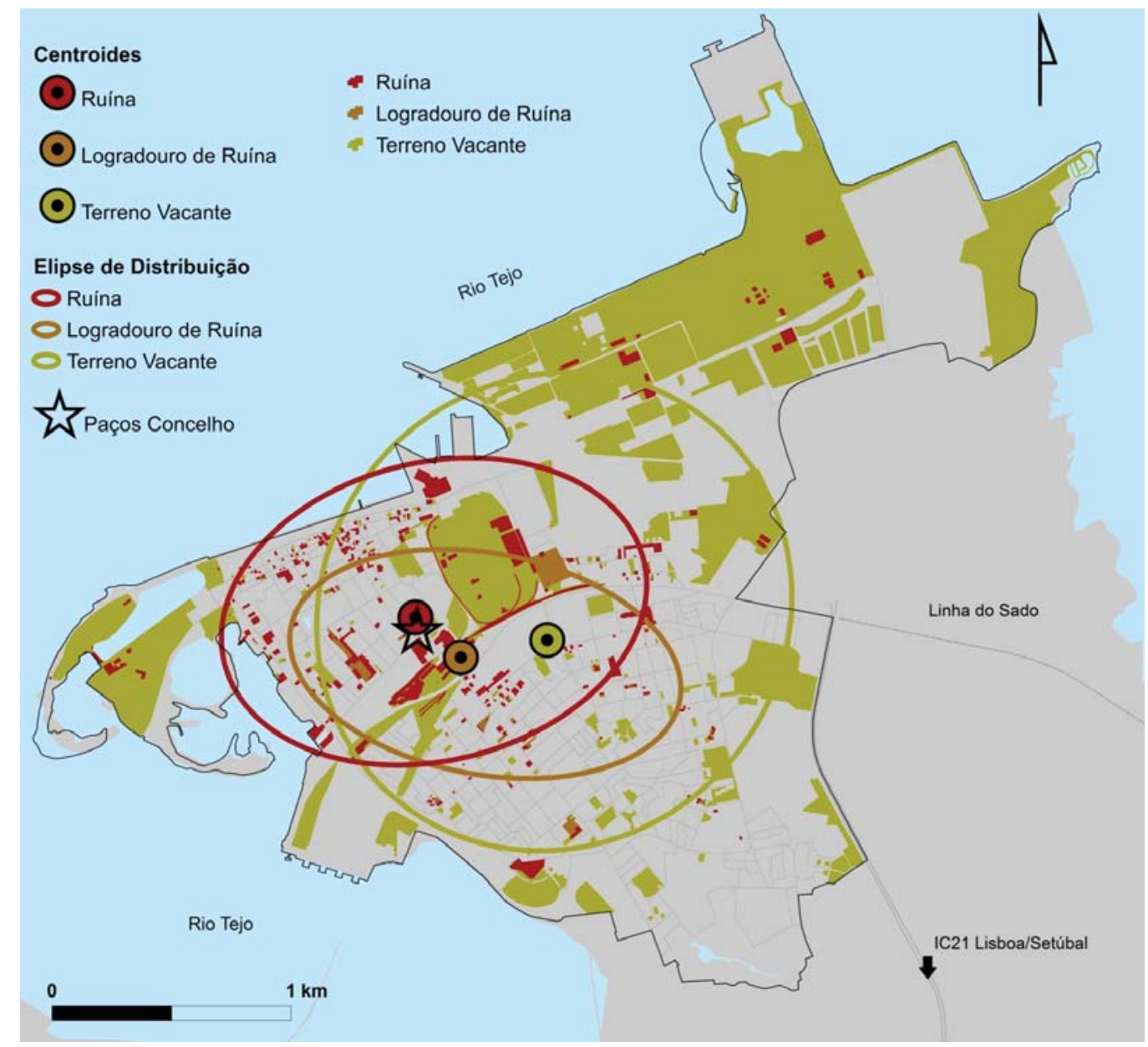

Fig. 1 - 'Perfurações' urbanas na cidade do Barreiro. Figura a cores disponível online.

Fig. 1 - Urban 'perforations' in Barreiro. Colour figure available online. 


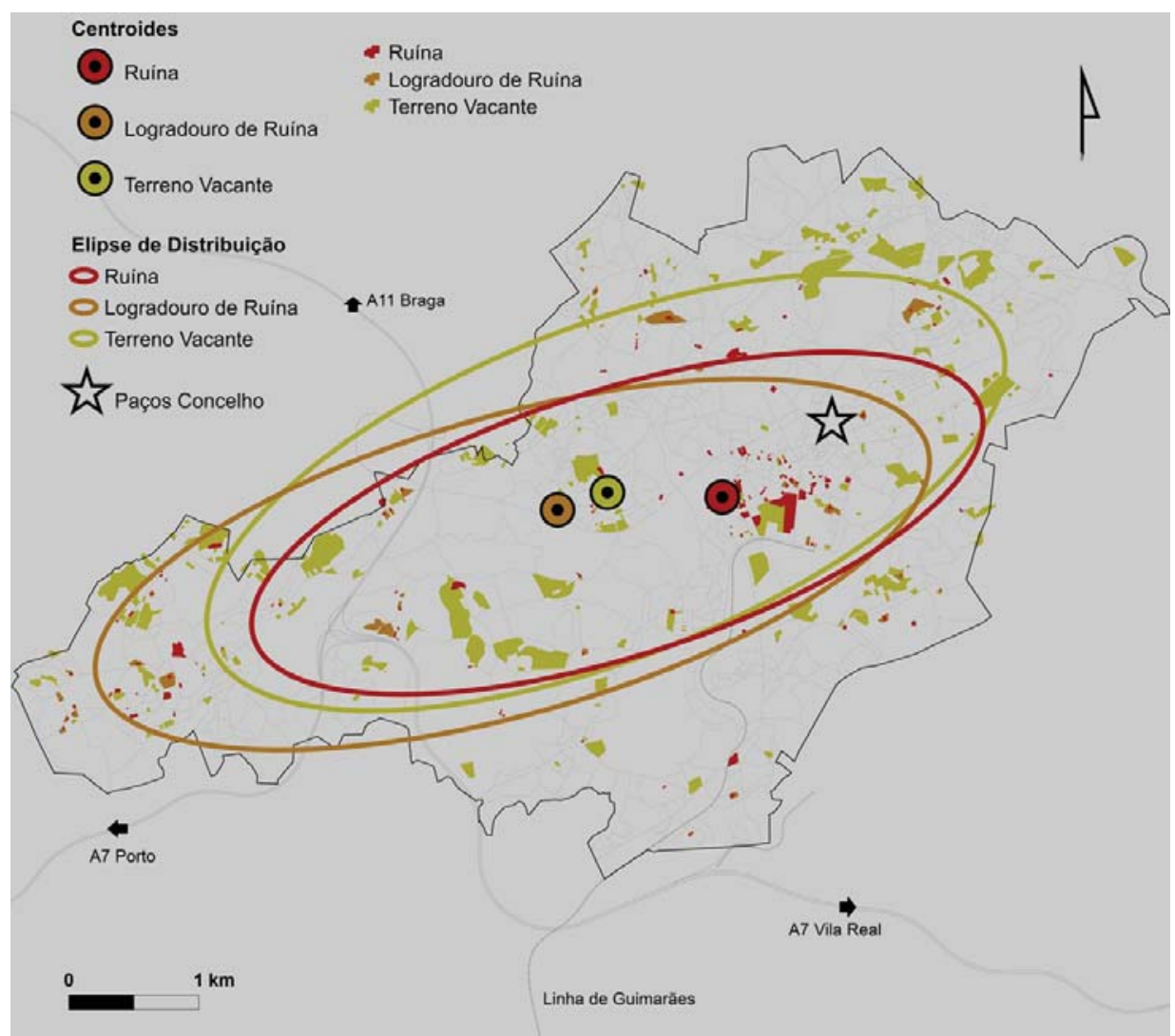

Fig. 2 - 'Perfurações' urbanas na cidade de Guimarães. Figura a cores disponível online.

Fig. 2 - Urban 'perforations' in Guimarães. Colour figure available online.

Fonte: elaboração própria a partir de ortofotomapas de 2015

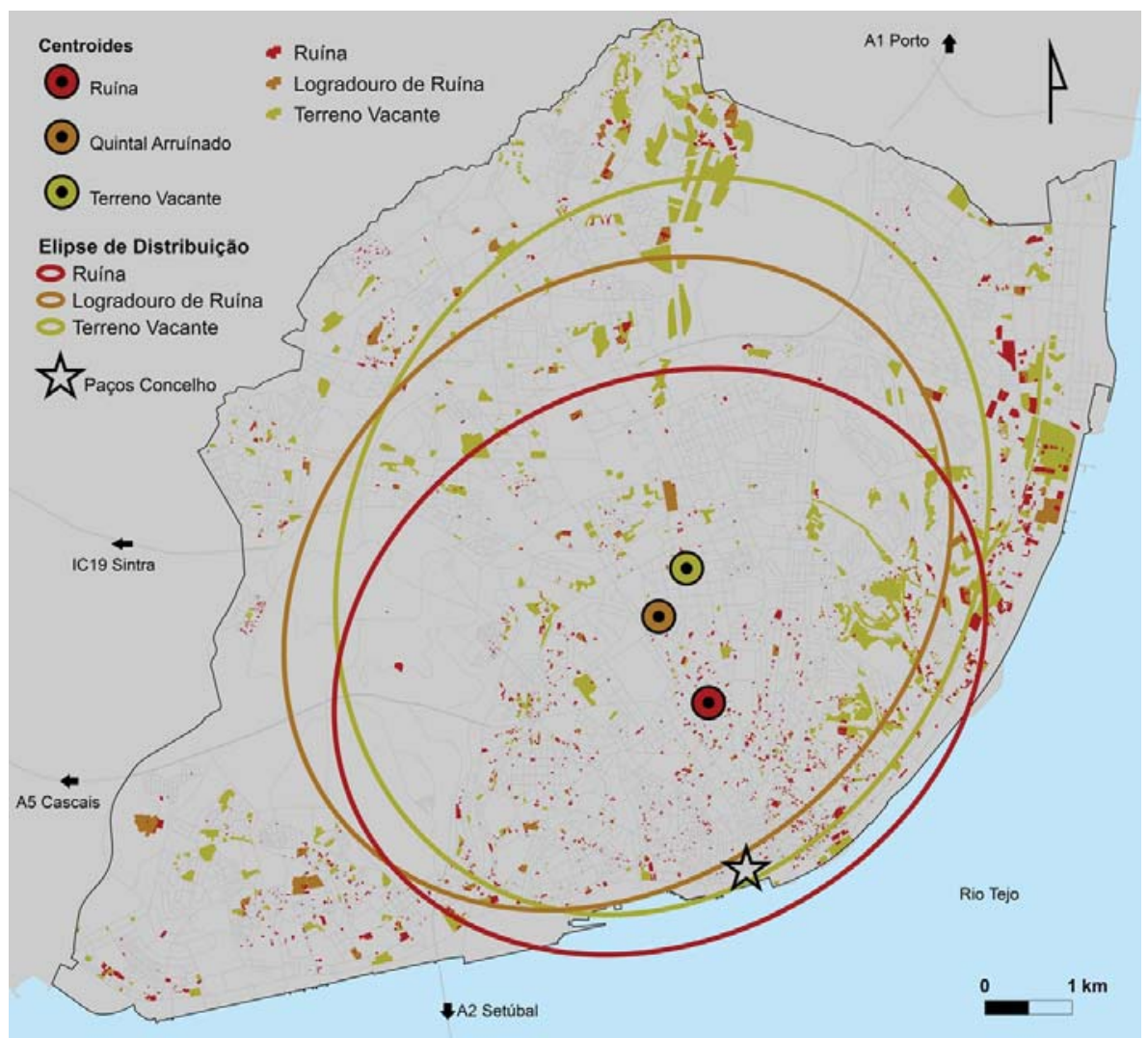

Fig. 3 - 'Perfurações' urbanas na cidade de Lisboa. Figura a cores disponível online.

Fig. 3 - Urban 'perforations' in Lisbon. Colour figure available online.

Fonte: elaboração própria a partir de ortofotomapas de 2014 


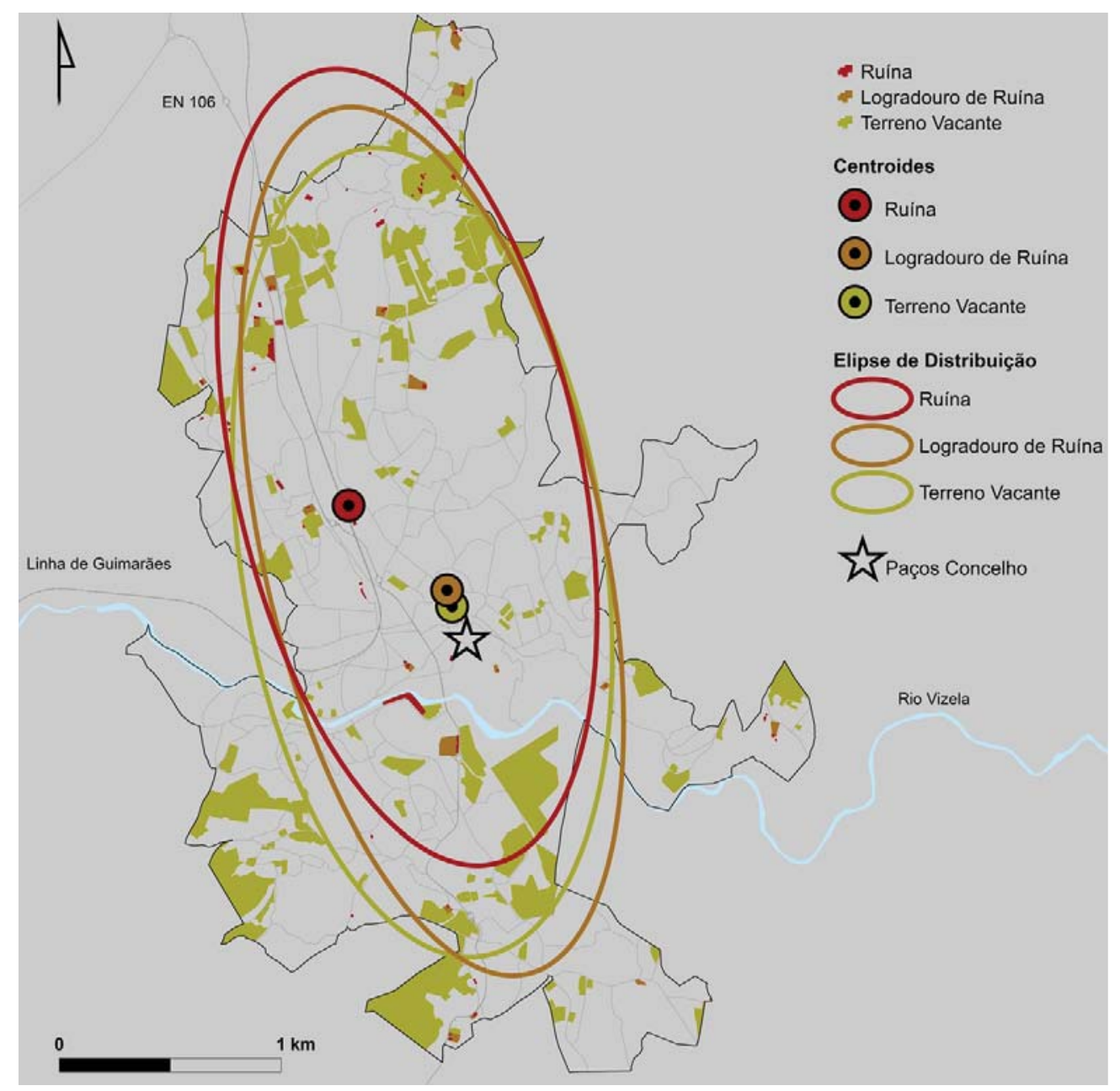

Fig. 4 - 'Perfurações' urbanas na cidade de Vizela. Figura a cores disponível online.

Fig. 4 - Urban 'perforations' in Vizela. Colour figure available online.

Fonte: elaboração própria a partir de ortofotomapas de 2015

Assim, podemos dizer que parecem existir neste conjunto de casos estudados três modelos diferentes de 'cidade perfurada', a saber:

i) um, representado por Lisboa, corresponde a um modelo com 'perfurações' mais numerosas e atomizadas, onde as ruínas estão mais difusamente presentes na paisagem e os terrenos vacantes surgem imbricados no tecido construído - um tipo 'microperfurado';

ii) um outro modelo de 'cidade perfurada', representado por Vizela e Guimarães, descreve uma situação em que o abandono se exprime mais pela vacância do que pelo arruinamento, e onde as 'perfurações' tendem a formar manchas mais extensas e contínuas - um tipo 'macroperfurado';

iii) e finalmente, temos o caso do Barreiro, representativo de um cenário de maior devastação, em que se combinam arruinamentos disseminados com vastos arrasamentos responsáveis pela produção de extensas vacâncias urbanas - um tipo 'multiperfurado'. 


\section{Localização e distribuição das 'perfurações' urbanas}

Tende a assumir-se intuitivamente que as ruínas se localizam em áreas centrais das cidades, onde há uma ocupação urbana mais antiga, e que os terrenos vacantes ocorrem sobretudo em áreas periféricas, onde a frente de urbanização ainda não chegou. Estudos recentes têm sugerido, no entanto, que o problema pode revestir feições mais complexas (Silverman et al., 2012; Brito-Henriques, 2017).

A simples análise da localização das 'perfurações' urbanas não é suficiente para se retirar uma conclusão clara sobre esta matéria (figs. 1 a 4). As imagens obtidas não denunciam uma regra óbvia na disposição das 'perfurações': mais do que qualquer sinal de concentração em partes determinadas das cidades, é a dispersão que predomina como tendência de localização dos vários tipos de 'perfurações'.

A determinação dos centroides e das elipses de desvio padrão (SDE) confirma essa ideia de dispersão dominante. Concentrações fortes dariam elipses circunscritas em torno dos respetivos centroides, de pequeno raio e tendencialmente circulares. As formas obtidas, para qualquer dos tipos de 'perfuração' e em qualquer das quatro cidades, diferem consideravelmente desse modelo, mas diferem de forma ainda mais notória nas duas cidades da sub-região do Ave, o que indicia a existência de um padrão superlativamente disperso. De facto, as SDE apresentam em Guimarães e Vizela, qualquer que seja o tipo de 'perfuração', formas especialmente oblongadas, sugerindo que ruínas e terrenos vacantes se dispersam nestas duas cidades mais distensamente no espaço, tendendo a ocorrer não tanto segundo um padrão concêntrico (i.e., com dispersão em torno de um núcleo), mas mais ao longo de eixos. Este modelo de dispersão tendencialmente axial tem que ver com a estrutura espacial dessas cidades e o seu processo de desenvolvimento específico. A cidade de Vizela desenvolveu-se ao longo da movimentada EN-106 (que vem de Guimarães, a norte, e segue para Penafiel, a sul), em redor da qual se foram adensando construções e funções urbanas, e é portanto em relação a esse eixo que se dispõem também as várias 'perfurações'. No caso de Guimarães, a forma da cidade descreve o desenvolvimento urbano preferencial dos últimos decénios, para sudoeste, orientado pela moderna rede de IP e autoestradas que conectam Guimarães a Braga, Vila do Conde e Porto. O perímetro urbano estendeu-se ao longo da variante que liga a área central da cidade, em redor do histórico Toural, ao nó de Silvares, pela veiga de Creixomil, e a disposição das perfurações urbanas no espaço segue, grosso modo, essa mesma orientação dominante.

Analisando em mais detalhe as imagens produzidas pelas diversas elipses de dispersão, percebem-se dissemelhanças não só entre as formas tendenciais de distribuição dos vários tipos de 'perfurações', mas também de cidade para cidade. Barreiro é onde há maiores diferenças nas formas e nos ângulos de rotação das elipses, o que sugere comunalidades mais baixas entre as variâncias espaciais dos vários tipos de 'perfurações'. Diferenças dessas não são tão sensíveis nos outros casos em estudo, onde o que há são sobretudo variações no tamanho das SDE (diferenças no raio) e de posição ao longo dos mesmos eixos direcionais. Assim, enquanto no Barreiro se vislumbra alguma tendência para os vários tipos de 'perfurações' ocorrerem mais disjuntamente no espaço - ruínas mais pre- 
sentes no Barreiro Antigo, terrenos vacantes mais presentes nos espaços da antiga CUF nas restantes cidades todos eles tendem a aparecer mais misturados na paisagem.

Quanto às diferenças no tamanho das várias SDE, constata-se que em Lisboa, Barreiro e Guimarães, as ruínas apresentam SDE visivelmente menores do que as outras 'perfurações'. Depreende-se disso que as ruínas terão, nessas cidades, distribuições menos dispersas do que os terrenos vacantes. Estes últimos surgem não só mais espalhados no espaço urbano, como parecem ser mais frequentes e formar polígonos de maior dimensão em posições periféricas, ganhando especial visibilidade na paisagem. Os maiores 'farrapos' de vacantes vão aparecer, em Lisboa, na Zona Oriental (Penha de França e Vale de Santo António, Chelas, Marvila), nas freguesias periféricas a norte da Segunda Circular, e na Ajuda; no Barreiro, além dos já referidos terrenos da antiga CUF, há extensas vacâncias na frente ribeirinha ocidental, e depois outros espaços menores na periferia sul da cidade e também a leste, na transição para o Lavradio; em Guimarães, terrenos vacantes de certa escala começam a ser encontrados logo em redor da parte mais densa e central da cidade, confinada à área entre Creixomil e Margaride. Algo de semelhante se passa, aliás, com os logradouros de ruínas, categoria que no fundo descreve as situações de estruturas arruinadas com terrenos envolventes de certa dimensão. Estas 'perfurações' são frequentemente restos de quintas de produção e de veraneio, situadas no que foram outrora os anéis periurbanos das respetivas cidades, entretanto abandonadas e engolidas pelo avanço da urbanização. Essas estruturas vão ocorrer por isso também mais dispersamente e mais periferizadas do que as outras ruínas. No caso de Vizela, porém, estas diferenças na forma de distribuição das ruínas e dos outros tipos de 'perfurações' não é tão percetível. O facto desta cidade ser menos densa e compacta pode explicar que estejam atenuadas as referidas nuances.

Para confirmarmos as observações anteriores, podemos comparar a posição dos centroides dos vários tipos de 'perfurações'. Este exercício serve para esclarecer se há diferenças na posição relativa de ruínas e terrenos vacantes no espaço urbano, e quais ocupam posições mais centrais e mais periféricas. Assumindo que a localização dos Paços do Concelho pode ser um indicador de centralidade urbana - enquanto referencial do centro histórico, cívico e funcional das cidades -, comparar as distâncias dos centroides a esses pontos e aos perímetros urbanos é uma forma possível de averiguar como ruínas, logradouros de ruínas e terrenos vacantes se posicionam face ao centro e à periferia das cidades.

A análise do quadro IV, onde esses valores estão sintetizados, confirma que não existe uma regra única nas quatro cidades estudadas. Não se pode dizer taxativamente que as ruínas ocorram sempre em posições mais centrais do que os terrenos vacantes, ou que tendam a situar-se preferencialmente em áreas centrais. De facto, enquanto em Lisboa e Guimarães constatamos que os centroides das ruínas se encontram mais próximos dos Paços do Concelho do que os centroides dos terrenos vacantes e dos logradouros de ruínas, e vice-versa no que respeita à distância aos limites urbanos, em Vizela sucede o oposto, com as ruínas a surgirem nessa cidade mais periferizadas do que os terrenos vacantes. Na cidade do Barreiro, embora o centroide das ruínas também esteja mais próximo dos Paços do Concelho do que os centroides das outras 'perfurações', tal como sucede em Lisboa e 
Guimarães, a distância desse centroide aos limites urbanos não é maior do que a dos outros centroides. Isto deve-se ao facto de muitas ruínas aparecerem junto aos limites da cidade, nomeadamente ao longo da frente ribeirinha, no Barreiro Antigo, e de, ao mesmo tempo, se encontrarem terrenos vacantes em localizações bastante centrais da cidade, nomeadamente associados a demolições industriais e infraestruturas ferroviárias abandonadas.

$$
\begin{gathered}
\text { Quadro IV - Distância dos centroides das 'perfurações' urbanas em relação ao centro } \\
\text { e periferia das cidades. }
\end{gathered}
$$

Table IV - Distance of the urban 'perforations' centroids in relation to the centre and periphery of cities.

\begin{tabular}{lccc|ccc}
\hline & \multicolumn{2}{c|}{$\begin{array}{c}\text { Distância euclidiana dos centroides } \\
\text { aos paços do concelho }(\mathbf{m})\end{array}$} & \multicolumn{3}{c}{$\begin{array}{c}\text { Distância euclidiana média dos centroides } \\
\text { ao perímetro urbano }(\mathbf{m})\end{array}$} \\
\hline & ruínas & $\begin{array}{c}\text { logradouros } \\
\text { de ruína }\end{array}$ & $\begin{array}{c}\text { terrenos } \\
\text { vacantes }\end{array}$ & ruínas & $\begin{array}{c}\text { logradouros } \\
\text { de ruína }\end{array}$ & $\begin{array}{c}\text { terrenos } \\
\text { vacantes }\end{array}$ \\
\hline Barreiro & 50 & 546 & 217 & 1565 & 1826 & 1671 \\
Guimarães & 1932 & 3492 & 3043 & 6527 & 5513 & 5692 \\
Lisboa & 1034 & 1819 & 2226 & 3016 & 2778 & 2739 \\
Vizela & 800 & 232 & 155 & 1528 & 1428 & 1434 \\
\hline
\end{tabular}

Tendo presente que as ruínas são o tipo de 'perfuração' com uma tendência apesar de tudo mais atenuada de dispersão, procedemos ao cálculo da Densidade de Kernel com o intuito de identificar eventuais sinais de 'clusterização' (fig. 5).

Os resultados obtidos mostram que as ruínas desenham nas cidades padrões espaciais granulosos, com vários nódulos de adensamento de diferentes dimensões e intensidades, que podem ter ou não continuidades entre si através dos halos, ou auréolas, que em seu redor se formam.

Nas quatro cidades estudadas, aquela que apresenta um padrão de distribuição das ruínas mais simples, mais consentâneo com um esquema de tipo centro-periferia, com uma evidente concentração das estruturas arruinadas numa área específica e central da cidade, é Guimarães. As ruínas aparecem fortemente concentradas a sul do centro histórico, no setor Creixomil-Caldeiroa-Couros, que corresponde a uma área de tradição industrial e habitação popular. Como no centro histórico propriamente dito, onde tem havido um esforço de política consistente desde há décadas de salvaguarda e reabilitação do património, as ruínas são raras ou inexistentes, é abusivo estabelecer um nexo entre este padrão de arruinamento e a antiguidade do edificado.

Nas outras cidades, os padrões são mais complexos, apresentando formas essencialmente polinucleadas. As topografias obtidas levam a pensar no arruinamento como um fenómeno contingente, que escapa às lógicas deterministas que tendem a opor centro e periferia. No Barreiro, identificam-se duas nucleações mais fortes na área urbana mais antiga, a norte, paralelamente à frente de rio, e na área central a sul da linha de caminho de ferro, em redor da Rua Miguel Bombarda, que corresponde a uma expansão moderna, da segunda metade do século XX, e que tradicionalmente era o eixo focal da cidade; outros focos secundários de arruinamento surgem em outras posições periféricas na cidade. Em 
Lisboa, as ruínas adensam-se fortemente a oriente da Baixa, nos bairros históricos de Mouraria, Alfama e Graça, prolongando-se até Xabregas, mas não estão especialmente presentes noutros setores do centro histórico. Nucleações secundárias com concentrações mais fortes de ruínas aparecem depois em certos pontos ao longo da frente ribeirinha, unidas por um halo de intensidade menor, mas estas não são significativamente mais importantes do que as concentrações de ruínas que existem em locais de urbanização mais recente e periférica como Campolide, o bairro da Boavista, Carnide ou Ameixoeira. Em Vizela, o arruinamento é sobretudo percetível ao longo da EN-106, e em especial no seu setor mais a norte, antes da chegada ao Rio Vizela. Todas estas imagens, reveladoras de uma tendência de aglutinação em polos, parecem corroborar a tese de que "O abandono propaga-se frequentemente por contágio" (Bowman \& Pagano, 2004, p. 2), ao mesmo tempo que confirmam a ideia de que o abandono na 'cidade perfurada' tende a desenhar uma "geografia aleatória" em que "frentes de arruinamento avançam nas periferias [...] ao mesmo tempo que continuam corroendo partes do centro" (Brito-Henriques, 2017, p. 268).

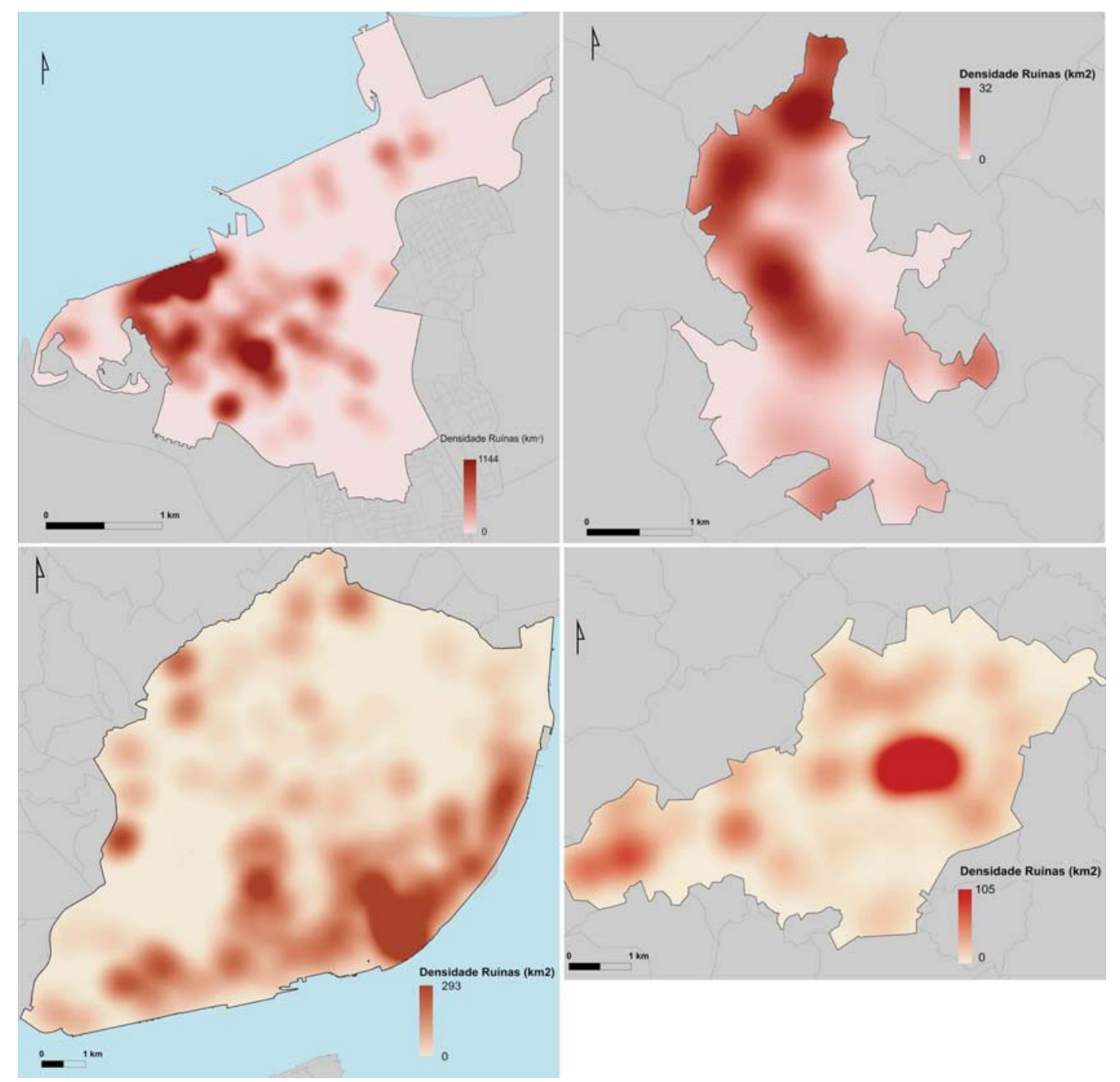

Fig. 5 - Densidade de Kernel de ruínas na cidade do Barreiro (a); Vizela (b); Lisboa (c) e Guimarães (d). Figura a cores disponível online.

Fig. 5 - Kernel density of ruins in Barreiro (a); Vizela (b); Lisboa (c) e Guimarães (d). Colour figure available online. 


\section{CONCLUSÃO}

Falar de 'cidade perfurada' para designar a consequência do encolhimento urbano ao nível morfológico parece ser, como se comprova neste artigo, uma opção adequada. A retração demográfica e a diminuição das funções urbanas exprimem-se na paisagem através da multiplicação de espaços abandonados - as 'perfurações' - que 'esburacam' o tecido urbano.

Os dados recolhidos mostram que a 'cidade perfurada' é uma realidade complexa e multiforme. A extensão, a densidade, a forma e o tipo das 'perfurações' varia bastante entre as cidades em função do seu passado, dos processos de urbanização que seguiram e da forma urbana, mas também do historial mais ou menos prolongado de encolhimento e da gravidade da crise a que estão ou estiveram sujeitas. Tanto quanto se consegue concluir da comparação das quatro cidades estudadas, encolhimentos mais prolongados e desindustrializações mais severas produzem mais ruínas e mais vacâncias decorrentes de demolições, que se traduzem em 'perfurações' de tamanhos mais variados mas também mais embutidas no tecido construído; em cidades com historiais de encolhimento mais recentes, os dados são sugestivos de que o arruinamento é menos percetível e de que predominam as vacâncias ligadas a solo expectante - talvez por a não concretização de intenções urbanísticas ser um dos primeiros sintomas da recessão demográfica e económica -, resultado assim em formas mais 'macroperfuradas'.

Colocámos no início deste estudo como uma das questões a investigar perceber de que maneira o abandono se exprime na paisagem urbana, se mais ou menos caoticamente, se prefigurando um padrão mais ou menos fragmentado, e ainda se de forma tendencialmente dispersa ou concentrada, e se com privilégio das localizações mais centrais ou mais periféricas. A este respeito, os resultados da investigação apontam para a predominância da dispersão sobre a concentração, da fragmentação sobre a continuidade, e de uma certa imprevisibilidade e irregularidade na geografia do abandono do espaço urbano.

Diferentes tipos de 'perfurações' e com diferentes distribuições na cidade podem ser encontradas. Construções em ruínas de grande dimensão são raras. Contudo, embora não sejam as mais frequentes, são ruínas deste tipo, como fábricas abandonadas, velhos palacetes, ou edifícios de equipamento (cineteatros, quartéis, garagens, etc.) que mais se impõem visualmente na paisagem pela sua imponência. Ruínas com grandes logradouros abandonados também não são muito comuns e tendem a aparecer preferencialmente em áreas periféricas das cidades, menos densas. Acompanham-nas muitas vezes nessas localizações grandes terrenos vacantes, que podem resultar de demolições de antigas estruturas edificadas - normalmente, industriais - mas que a mais das vezes são espaços expectantes, incultos, que se impõem como intromissões 'selvagens' no perímetro urbano. Normalmente vistos como indesejáveis pelo sistema de planeamento, estes espaços contêm um potencial ecológico que merece ser estudado e valorizado.

Em todas as cidades estudadas, porém, o mais comum são os pequenos arruinamentos de edifícios residenciais, que ocorrem disseminados pelo tecido urbano. Misturados com essas estruturas arruinadas, aparecem também pequenos vacantes resultantes de 
demolições nos tecidos mais densos e consolidados das áreas centrais das cidades, criando 'buracos' nos volumes construídos que podem ser mais ou menos extensos, interrompendo a continuidade dos alçados das ruas e abrindo por vezes inesperadas passagens pelos quarteirões. Uma conclusão a reter do estudo que realizámos é que essa dispersão, porém, não é insensível à proximidade. Apesar de um certo caráter contingente que parece ser inerente ao arruinamento, pudemos constatar que as ruínas tendem a 'clusterizar-se', formando polinucleações, o que é compatível com uma certa ideia de contágio no arruinamento do espaço edificado.

\section{AGRADECIMENTOS}

Este estudo é financiado por fundos nacionais através da FCT - Fundação para a Ciência e a Tecnologia, I.P., no âmbito do Projeto PTDC/ATP-EUR/1180/2014 (NoVOID - Ruinas e terrenos vagos nas cidades portuguesas: Explorando a vida obscura dos espaços urbanos abandonados e propostas de planeamento alternativo para a cidade perfurada), do qual é um produto.

Os autores agradecem a Ana Baptista e Anita Bozek a colaboração no processo de recolha de dados (fase de fotointerpretação).

\section{REFERÊNCIAS BIBLIOGRÁFICAS}

Abrantes, P., Rocha, J., Costa, E. M., Gomes, E., Morgado, P., \& Costa, N. (2017). Modelling urban form: A multidimensional typology of urban occupation for spatial analysis. Environment and Planning B: Urban Analytics and City Science. doi: 10.1177/2399808317700140.

Accordino, J., \& Johnson, G. T. (2000). Addressing the vacant and abandoned property problem. Journal of Urban Affairs, 22(3), 301-315.

Alker, S., Joy, V., Roberts, P., \& Smith, N. (2000). The definition of brownfield. Journal of Environmental Planning and Management, 43(1), 49-69.

Audirac, I., Cunningham-Sabot, E., Fol, S., \& Torres Moraes, S. (2012). Declining suburbs in Europe and Latin America. International Journal of Urban and Regional Research, 36(2), 226-244.

Berger, A. (2006). Drosscape: Wasting land in urban America. Princeton, NJ: Princeton Architectural Press.

Bontje, M. (2004). Facing the challenge of shrinking cities in East Germany: The case of Leipzig. GeoJournal, 61(1), 13-21.

Bowman, A. O. M., \& Pagano, M. A. (2004). Terra Incognita: Vacant land and urban strategies. Washington, D.C.: Georgetown University Press.
Brito-Henriques, E. (2017). Arruinamento e regeneração do espaço edificado na metrópole do século XXI: o caso de Lisboa [Ruination and regeneration of the built environment in the 21st Century's metropolis: the case of Lisbon]. EURE Revista Latinoamericana de Estudios Urbano Regionales, 43(128), 251-272.

Coleman, A. (1982). Dead space in the dying inner city. International Journal of Environmental Studies, 19(2), 103-107.

Couch, C., \& Cocks, M. (2013). Housing vacancy and the shrinking city: trends and policies in the UK and the city of Liverpool. Housing Studies, 28(3), 499-519.

Edensor, T. (2005). Industrial ruins: Spaces, aesthetics and materiality. New York: Berg.

Fernandes, M. (2015). O estudo da forma urbana em Portugal, entre os geógrafos [The study of urban form in Portugal among the geographers]. In V. Oliveira, T. Marat-Mendes \& $\mathrm{P}$. Pinho (Eds.), O estudo da forma urbana em Portugal [The study of urban form in Portugal] (pp. 55-64). Porto: Universidade do Porto Edições. 
Florentin, D. (2010). The "perforated city": Leipzig's model of urban shrinkage management. Berkeley Planning Journal, 23(1), 83-101.

Gatrell, A. C., Bailey, T. C., Diggle, P. J., \& Rowlingson, B. S. (1996). Spatial point pattern analysis and its application in geographical epidemiology. Transactions of the Institute of British Geographers, 21(1), 256-274.

Grădinaru, S. R., Iojă, C. I., Onose, D. A., Gavrilidis, A. A., Pătru-Stupariuc, I... Hersperger, A. M. (2015). Land abandonment as a precursor of built-up development at the sprawling periphery of former socialist cities. Ecological Indicators, 57, 305-313.

Greenberg, M. R., Popper, F. J., \& West, B. M. (1990). The TOADS: a new American epidemic. Urban Affairs Review, 25(3), 435-454.

Haase, A., Rink, D., Großmann, K., Bernt, M., \& Mykhnenko, V. (2014). Conceptualizing urban shrinkage. Environment and Planning A, 46(7), 1519-1534 .

Hillier, A. E., Culhane, D. P., Smith, T. E., \& Tomlin, C. D. (2003). Predicting housing abandonment with the Philadelphia Neighborhood Information System. Journal of Urban Affairs, 25(1), 91-105.

Hollander, J. (2011). Sunburnt cities: The Great Recession, depopulation, and urban planning in the American Sunbelt. London and New York: Routledge.

Hollander, J., Pallagst, K., Schwarz, T., \& Popper, F. (2009). Planning shrinking cities. Progress in Planning, 72(4), 223-232.

Instituto Nacional de Estatística. (INE). (2013). Censos 2011 [Census 2011]. Retrived from http://censos.ine.pt/xportal/xmain?xpgid=censos 2011 apresentacao\&xpid=CENSOS

Instituto Nacional de Estatística. (INE). (2002). Censos 2001 [Census 2001]. Retrived from http://censos.ine.pt/xportal/xmain?xpid=INE\&xpgid= censos_historia_pt

Lütke Daldrup, E. (2003). Die perforierte Stadt - neue Raüme im Leipziger Osten [The perforated city - new spaces in Eastern Leipzig]. Information zur Raumentwicklung, 1/2, 55-67.

Mallach, A. (2011). Demolition and preservation in shrinking US industrial cities. Building Research \& Information, 39(4), 380-394.

Martinez-Fernandez, C., Audirac, I., Fol, S., \& Cunningham-Sabot, E. (2012). Shrinking cities: urban challenges of globalization. International Journal of Urban and Regional Research, 36(2), 213-225.

Morgado, P. (2011). Efeito estruturante das redes de transporte no território. Modelo de análise [Road network structural effect on territory. A geographical model]. (Tese de Doutoramento). Lisboa: Universidade de Lisboa.

Munroe, D. K., van Berkel, D. B., Verburg, P. H., \& Olson, J. L. (2013). Alternative trajectories of land abandonment: causes, consequences and research challenges. Current Opinion in Environmental Sustainability, 5(5), 471-476.

Németh, J., \& Langhorst, J. (2014). Rethinking urban transformation: temporary uses for vacant land. Cities, 40(B), 143-150.

Newman, G. D., Bowman, A. O. M., Lee, R. J., \& Kim, B. (2016). A current inventory of vacant urban land in America. Journal of Urban Design, 21(3), 302-319.

Northam, R. M. (1971). Vacant urban land in the American city. Land Economics, 47(4), 345-355.

Pagano, M. A., \& Bowman, A. O. M. (2000). Vacant land in cities: an urban resource. Brookings Center on Urban \& Metropolitan Policy Survey Series. Retrievied from https://www.brookings.edu/ research/vacant-land-in-cities-an-urban-resource/

Panagopoulos, T., \& Barreira, A. P. (2013). Understanding the shrinkage phenomenon in Portugal. WSEAS Transactions on Environment and Development, 9(1), 1-12.

Pearsall, H., Lucas, S., \& Lenhardt, J. (2014). The contested nature of vacant land in Philadelphia and approaches for resolving competing objectives for redevelopment. Cities, 40(B), 163-174.

Queirós. M. (2005). Reestruturação económica e planeamento urbano: o caso da Quimiparque no Barreiro [Economic restructuring and urban planning: the case of Quimiparque in Barreiro]. In M. Vale (Ed.), Desinvestimento e território. Estudos de caso em Portugal [Divestment and territory. Case studies in Portugal] (pp. 23-46). Lisboa: Centro de Estudos Geográficos.

Queirós, M., \& Brito-Henriques, E. (2001). Reconversão de áreas desindustrializadas: considerações e metodologia de investigação [Redevelopment of deindustrialized spaces: considerations and 
research methodology]. In $M$. Vale (Ed.), DivesT - Desinvestimento e impactos económicos, sociais e territoriais. Actas [Divestment and economic, social and spatial impacts. Proceedings] (pp. 171-184). Lisboa: Centro de Estudos Geográficos.

Reckien, D., \& Martinez-Fernandez, C. (2011). Why do cities shrink? European Planning Studies, 19(8), 1375-1397.

Reis, J., \& Silva, E. (2015). O uso de métricas espaciais para a análise e caracterização da forma urbana [The use of spatial metrics for the analysis and characterization of urban form]. In V. Oliveira, T. Marat-Mendes \& P. Pinho (Eds.), O estudo da forma urbana em Portugal [The study of urban form in Portugal] (pp. 97-122). Porto: U. Porto Edições.

Rieniets, T. (2009). Shrinking cities: causes and effects of urban population losses in the twentieth century. Nature and Culture, 4(3), 231-254.

Santos, J. R. (2018). Espaços infraestruturais e vacância: traços diacrónicos na formação do território metropolitano de Lisboa [Infrastructural spaces and vacancy: diachronic traces in the shaping of Lisbon's metropolitan territory]. Finisterra - Revista Portuguesa de Geografia, LIII(108), 135-159.

Schmidt, S. (2011). Sprawl without growth in Eastern Germany. Urban Geography, 32(1), 105-128.

Silverman, B. (1986). Density estimation for statistics and data analysis. Londres: Chapman and Hall.

Silverman, R. M., Yin, L., \& Patterson, K. L. (2012). Dawn of the dead city: An exploratory analysis of vacant addresses in Buffalo, Ny 2008-2010. Journal of Urban Affairs, 35(2), 131-152.

Solà-Morales, I. (1995). Terrain vague [Wasteland]. In C. Davidson (Ed.), Anyplace (pp. 118-123). Cambridge, MA: MIT Press.

Wiechmann, T. (2008). Errors expected - Aligning urban strategy with demographic uncertainty in shrinking cities. International Planning Studies, 13(4), 431-446.

Wiechmann, T., \& Pallagst, K. (2012). Urban shrinkage in Germany and the USA: A comparision of transformation patterns and local strategies. International Journal of Urban and Regional Research, 36(2), 261-280.

i Por ser exceção neste panorama, merece referência o trabalho desenvolvido pelo núcleo MOPT do Centro de Estudos Geográficos (IGOT) da Universidade de Lisboa (v. Abrantes, Rocha, Costa, Gomes, Morgado \& Costa, 2017).

ii Por exemplo, se não havia imagens Street View do mesmo ano do ortofotomapa, confrontavam-se imagens em anos anteriores e posteriores para inferir a situação no momento intermédio e confirmar a identificação feita com base na foto-interpretação vertical.

iii A medida de centralidade é uma função determinada a partir do somatório das distâncias euclidianas entre um objeto e todos os outros objetos espaciais (Morgado, 2011).

iv A elipse do desvio padrão mede e representa a existência ou não de uma tendência de distribuição espacial em torno do objecto central e para uma estrutura de objetos (Morgado, 2011).

v A Densidade de Kernel é uma medida de estimação criada a partir de uma técnica de interpolação probabilística e de análise de padrões espaciais de pontos que permite identificar, a partir de um conjunto de pontos conhecidos, a magnitude de um determinado objeto ou evento por unidade de área, ou seja a densidade do objecto ou evento numa determinada vizinhança (Silverman, 1986; Gatrell, Bailey, Diggle, \& Rowlingson, 1996).

vi A CUF foi, até à sua nacionalização em 1975 (depois designada Quimigal), o maior grupo económico português, em cujas mãos estava um conglomerado de mais de uma centena de empresas e 110000 empregados, com atividade distribuída pela indústria (química, metalomecânica, produtos elétricos e eletrônicos, têxtil, etc.), serviços financeiros, saúde e turismo (Queirós, 2005). A sede do grupo e o seu principal parque industrial estavam localizados no Barreiro.

vii O LPI (Large Patch Index) é uma medida de fragmentação dada pela razão entre a área do maior polígono de uma dada categoria de espaços e a área total da paisagem ocupada por essa categoria de espaços. O LPI varia entre os limites teóricos de 0 e 100. A fragmentação é tanto maior quanto mais próximo de 0 for o valor do LPI. 